\title{
Research
}

\section{Different mechanisms of fear extinction dependent on length of time since fear acquisition}

\author{
Karyn M. Myers, 2,3,4 Kerry J. Ressler, ${ }^{1,2,3}$ and Michael Davis ${ }^{1,2,3}$ \\ ${ }^{1}$ Department of Psychiatry and Behavioral Sciences, ${ }^{2}$ Center for Behavioral Neuroscience, and ${ }^{3}$ Yerkes National Primate Research \\ Center, Emory University Atlanta, Georgia 30329, USA
}

\begin{abstract}
Fear extinction is defined as a decline in conditioned fear responses (CRs) following nonreinforced exposure to a feared conditioned stimulus (CS). Behavioral evidence indicates that extinction is a form of inhibitory learning: Extinguished fear responses reappear with the passage of time (spontaneous recovery), a shift of context (renewal), and unsignaled presentations of the unconditioned stimulus (reinstatement). However, there also is evidence to suggest that extinction is an "unlearning" process corresponding to depotentiation of potentiated synapses within the amygdala. Because depotentiation is induced more readily at short intervals following LTP induction and is not inducible at all at a sufficient delay, it may be that extinction initiated shortly following fear acquisition preferentially engages depotentiation/ "unlearning," whereas extinction initiated at longer delays recruits a different mechanism. We investigated this possibility through a series of behavioral experiments examining the recoverability of conditioned fear following extinction. Consistent with an inhibitory learning mechanism of extinction, rats extinguished 24-72 h following acquisition exhibited moderate to strong reinstatement, renewal, and spontaneous recovery. In contrast, and consistent with an erasure mechanism, rats extinguished 10 min to $1 \mathrm{~h}$ after acquisition exhibited little or no reinstatement, renewal, or spontaneous recovery. These data support a model in which different neural mechanisms are recruited depending on the temporal delay of fear extinction.
\end{abstract}

A great deal is now known about the neural mechanisms of fear memory acquisition, consolidation, and expression, including the pathways through which these processes are mediated as well as many of the physiological and molecular changes underlying them (for reviews, see Davis 2000; Rodrigues et al. 2004). In contrast, the mechanisms of fear inhibition or suppression remain largely unknown, although interest in this question is growing in part due to recognition that disturbances of neural systems that inhibit fear responses are likely to underlie anxiety disorders in clinical populations (cf. Quirk and Gehlert 2003).

The major model system for the study of fear inhibition in the laboratory is extinction, in which an organism previously trained to fear a conditioned stimulus (CS; e.g., a light) through pairings of that stimulus with an aversive unconditioned stimulus (US; e.g., footshock) subsequently is exposed to the CS in the absence of the US until the fear conditioned response disappears. Extinction does not result from forgetting because the fear response lasts months, even years, in the absence of additional training following fear acquisition (Gale et al. 2004). The mechanism of extinction has been the subject of some debate historically, although it is now generally agreed that extinction is a form of new learning rather than an erasure or "unlearning" of conditioned fear. This conclusion is based on the re-emergence of extinguished fear responses with the passage of time (spontaneous recovery) (Pavlov 1927; Robbins 1990), following unsignaled exposure to the US (reinstatement) (Rescorla and Heth 1975; Bouton and Bolles 1979a; Westbrook et al. 2002), or when tested in a context different from the one in which extinction training took place (renewal) (Bouton and Bolles 1979b; Bouton and Swartzentruber 1986). Most current theories propose that extinction involves an active inhibition of fear and emphasize the role

${ }^{4}$ Corresponding author.

E-mail kmmyers@emory.edu; fax (404) 727-8070.

Article and publication are at http://www.learnmem.org/cgi/doi/10.1101/ Im.119806 of context in gating the expression of inhibition (cf. Bouton 1993).

Consistent with this conception, neural investigations of extinction have revealed several similarities to the mechanisms of acquisition. For example, fear extinction is dependent on $\mathrm{N}$ methyl-D-aspartate receptors (NMDARs) and L-type voltage-gated calcium channels (L-VGCCs) (Falls et al. 1992; Cain et al. 2001; Walker et al. 2002); is sensitive to modulation of second messenger systems, including kinase and phosphatase activity (Lu et al. 2001; Lin et al. 2003a,b; Szapiro et al. 2003; Chen et al. 2005; Yang and Lu 2005); and may require protein synthesis (Vianna et al. 2001; Lin et al. 2003b; Santini et al. 2004; Yang and Lu 2005; but see Lattal and Abel 2001; Fischer et al. 2004; Lattal et al. 2004). Some conditioned single unit responses to the CS within the basolateral amygdala (BLA) persist through extinction (Repa et al. 2001) and can be modulated by context following extinction training in a cellular correlate of renewal (Hobin et al. 2003). Extinction may engage GABAergic interneurons and/or intercalated cell populations within the amygdala (Harris and Westbrook 1998; Chhatwal et al. 2005), perhaps under the control of efferent structures such as prefrontal cortex (Quirk et al. 2000, 2003; Milad and Quirk 2002; Rosenkranz et al. 2003; Berretta et al. 2005), so as to effectively inhibit amygdalar activation by the CS following extinction training (Davis and Myers 2002; Myers and Davis 2002).

Recently, however, new data have emerged in support of a mechanism more consistent with an "unlearning" account of extinction, in which plasticity underlying fear memory is reversed through a process known as synaptic depotentiation. "Depotentiation" refers to a reversal of long-term potentiation (LTP; i.e., a return of potentiated synapses to baseline synaptic efficacy) when low-frequency or theta-frequency stimulation is applied to afferent pathways shortly following LTP induction. Evidence indicates that the biochemical and molecular mechanisms of depotentiation are opposite those of LTP. Thus, LTP is associated with phosphorylation of several second messengers and tran- 
scription factors including CaMKII, Akt, and MAPK; downregulation of phosphatase activity; and phosphorylation and membrane insertion of AMPA receptors (for reviews, see Riedel 1999; Malinow and Malenka 2002; Waltereit and Weller 2003). Depotentiation, in contrast, is associated with dephosphorylation of Akt, MAPK, and perhaps CaMKII; up-regulation of protein phosphatases including calcineurin and PP1; and dephosphorylation and internalization of AMPA receptors (for review, see Zhou and Poo 2004; see also Lin et al. 2003c). Thus, whereas LTP-inducing high-frequency stimulation (HFS) engages second messenger cascades culminating in gene transcription and protein synthesis, depotentiation-inducing low-frequency stimulation (LFS) counteracts those effects at every level.

Po-Wu Gean and colleagues have demonstrated that depotentiation occurs in the amygdala in vitro (Lin et al. 2003c, 2005; see also Aroniadou-Anderjaska et al. 2001) and that its induction shares some key features with fear extinction in the behaving animal. For example, both depotentiation and extinction are blocked by NMDAR and L-VGCC channel antagonists as well as inhibitors of calcineurin (Lin et al. 2003a,b). Both depotentiation and extinction are also associated with an increase in calcineurin activity within the amygdala, as well as a reversal of fear- or LTP-associated increases in phosphorylated Akt (see also Cannich et al. 2004). Finally, depotentiation-inducing low-frequency stimulation (LFS) of the amygdala in vivo 10 min after fear acquisition blocks the expression of conditioned fear $24 \mathrm{~h}$ later, an effect that could be interpreted as a mimicking of extinction (Lin et al. 2003c).

These findings are intriguing but puzzling because they would seem to offer no explanation of recovery of fear following extinction through spontaneous recovery, reinstatement, and renewal. However, as in any case in which apparently incongruent observations of the same system emerge, it may be useful to consider that both contain an element of truth. Certainly, although "new learning" and "unlearning" mechanisms of extinction often are presented as mutually exclusive possibilities, it has been acknowledged that both may occur to some extent (e.g., Delamater 2004). One possibility is that one or the other mechanism predominates under different experimental conditions. If so, then it should be possible to identify and manipulate those variables and as a result, observe extinction as "unlearning" and extinction as "new learning" in separate groups in a single experiment.

Clues as to the variables promoting "unlearning" may be evident in the features of synaptic depotentiation. For example, depotentiation is inducible more readily at short intervals following LTP induction and does not seem to be inducible at all at intervals greater than $\sim 1 \mathrm{~h}$ (Staubli and Chun 1996; Fujii et al. 1991; Huang et al. 2001). Few extinction studies have involved intervals between acquisition and extinction training of $<24 \mathrm{~h}$, although very recently it has been reported that the L-VGCC dependence of fear extinction in mice is not apparent when extinction training is conducted immediately following acquisition but is apparent when extinction is conducted at intervals of $1 \mathrm{~h}$ or $3 \mathrm{~h}$ (Cain et al. 2005), consistent with a changing mechanism of extinction dependent on the interval at which extinction training is initiated.

The current experiments were designed to examine more directly the hypothesis that the mechanism of extinction may differ depending on the interval at which extinction training is initiated, being more akin to "erasure" at short intervals and "new learning" at longer intervals. We predicted that extinction initiated shortly after fear conditioning (e.g., $10 \mathrm{~min}$ ) would not be susceptible to reinstatement, renewal, or spontaneous recovery, whereas extinction initiated at longer intervals (e.g., $72 \mathrm{~h}$ ) would exhibit all of these effects.

\section{Results}

\section{Experiment 1: Reinstatement}

Reinstatement was first observed by Rescorla and Heth (1975) and originally was taken to support a theoretical account of extinction in which the value of the US representation becomes deflated over the course of nonreinforced presentations of a CS formerly paired with that US. However, contrary to what would be expected from the US devaluation account, subsequent work indicated that reinstatement is context dependent such that unsignaled US presentations must occur within the context in which animals are tested if recovery is to be observed, and extinction (nonreinforced exposure) to context between unsignaled US presentations and test attenuates CR recovery (Bouton and Bolles 1979a; Bouton and King 1983). Thus, reinstatement appears to be due in large part to summation of two fearinducing tendencies, each behaviorally subthreshold when considered independently but suprathreshold when combined (cf. Reberg 1972; Hendry 1982): weak conditioning to context and residual excitation to the extinguished CS (Westbrook et al. 2002). Reinstatement would, therefore, seem to indicate that conditioning to the CS survives extinction, that is, that extinction does not completely erase previously acquired fear.

The experimental protocol is shown schematically in the top panel of Figure 1. Rats were trained to fear a light CS through 15 light-shock pairings, then at one of four time points thereafter (10 min or 1,24 , or $72 \mathrm{~h}$ ), they were extinguished through exposure to 90 lights in the absence of footshock. All rats were tested for extinction retention (post-extinction test) $24 \mathrm{~h}$ after extinction training. Several days thereafter ( $11 \mathrm{~d}$ after acquisition for all groups), the rats were exposed to five unsignaled footshocks, and $24 \mathrm{~h}$ after shock exposure, they were retested (reinstatement test).

The data from the two test sessions are shown in the bottom panel of Figure 1. The mean of only the first five trials of the reinstatement test is shown because reinstated fear responses rap-

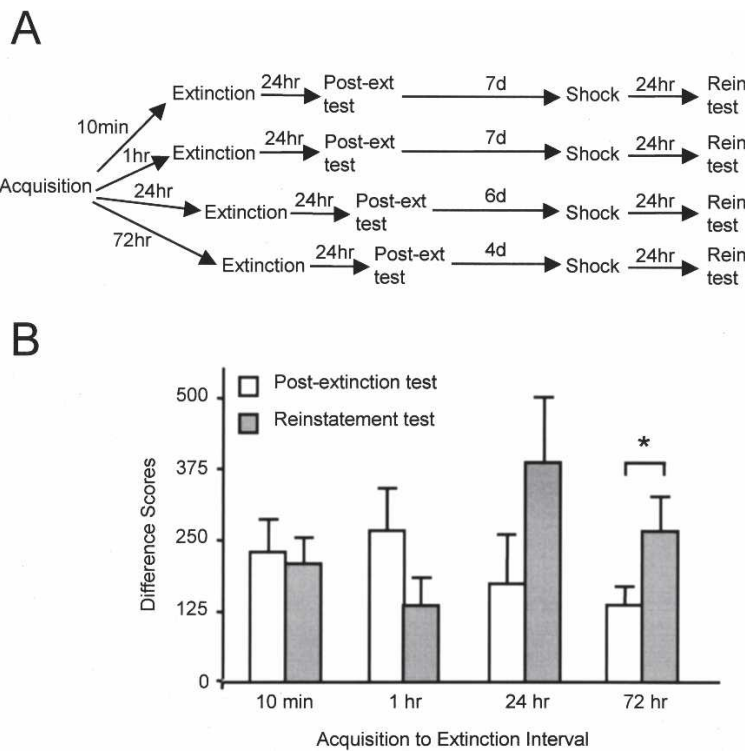

Figure 1. (A) Training protocol, Experiment 1. (B) Animals extinguished at intervals of $10 \mathrm{~min}, 1 \mathrm{~h}, 24 \mathrm{~h}$, or $72 \mathrm{~h}$ after fear acquisition exhibited differential susceptibility to reinstatement following unsignaled shock exposure. Shown are mean (+/ - SEM) fear-potentiated startle difference scores to a light CS in test sessions conducted $24 \mathrm{~h}$ after extinction training (post-extinction test) and $24 \mathrm{~h}$ after unsignaled shock exposure (reinstatement test). Significant differences $(P<0.05)$ are indicated by an asterisk. 
idly re-extinguished during the test session and returned to baseline by the sixth test trial. Inspection of the figure indicates that performance in the two tests differed significantly among the groups, such that animals extinguished 24 or $72 \mathrm{~h}$ after acquisition exhibited robust recovery of fear to the light subsequent to unsignaled shock presentations, whereas animals extinguished 1 $\mathrm{h}$ or $10 \mathrm{~min}$ after acquisition exhibited little or no fear recovery. Because analysis of reinstatement early in the test is the most sensitive way to assess reinstatement, the lack of increase in the 10-min and 1-h groups is especially noteworthy.

Statistical analyses supported these observations. An ANOVA with Group (10 min, $1 \mathrm{~h}, 24 \mathrm{~h}, 72 \mathrm{~h}$ ) as a between-groups factor and Test (post-extinction test, reinstatement test) as a repeated measure indicated a significant Group $\times$ Test interaction, $F_{3,52}=3.78, P=0.016$. Planned comparisons of the postextinction test versus the reinstatement test in each group revealed significant reinstatement in the 72 -h group only, $t_{(15)}=-2.64, P=0.018$. Reinstatement in the 24-h, 1-h, and 10min groups did not reach significance, as indicated by paired t-tests: $24 \mathrm{~h}, t_{(9)}=-1.48, P=0.174 ; 1 \mathrm{~h}, t_{(17)}=1.90, P=0.075 ; 10$ $\min , t_{(11)}=0.28, P=0.412$.

There appeared to be differences among the time-point groups in the post-extinction test, such that animals extinguished $10 \mathrm{~min}$ or $1 \mathrm{~h}$ after acquisition showed somewhat poorer extinction than did animals extinguished $24 \mathrm{~h}$ or $72 \mathrm{~h}$ after acquisition. However, a one-way ANOVA on the data from the post-extinction test indicated no simple main effect of group, $F_{3,52}<1$.

The lack of reinstatement in animals extinguished 10 min or $1 \mathrm{~h}$ after fear acquisition is noteworthy for several reasons. First, it cannot be dismissed as experimental artifact because reinstatement was observed in a separate group trained at the same time and under the same circumstances (the 72-h group). In other words, the 72-h group effectively serves as a positive control and indicates that short-interval extinction is not sensitive to reinstatement using parameters that are sufficient to produce reinstatement following extinction at longer intervals. Second, and more importantly, the lack of reinstatement in the 10-min and 1-h groups suggests that short-interval extinction proceeds by a different mechanism than does long-interval extinction, although the nature of the difference is unclear based on these data alone. One possibility is that the difference is quantitative, that is, that short-interval extinction proceeds via an inhibitory learning mechanism that happens to be stronger or more efficient than that underlying long-interval extinction. Alternatively, the difference could be qualitative, if short-interval extinction involved a mechanism not based on inhibitory learning, such as erasure.

To disentangle these possibilities and provide independent evidence for different mechanisms of short- and long-interval extinction, additional tests are needed.

\section{Experiment 2: Renewal}

One such test is renewal, which refers to a reappearance of extinguished CRs when animals are tested in a context different from the one in which extinction training took place. For example, when animals first are trained to fear a light CS in context $\mathrm{A}$, then receive extinction training to the light in context $\mathrm{B}$, and finally are tested for fear to the light in either context A or context B, different outcomes are obtained: Animals tested in context B exhibit little fear to the light, whereas animals tested in context A exhibit robust fear to the light (Bouton and Bolles 1979b; Bouton and King 1983). A similar post-extinction return of fear is observed when animals are tested in a third, novel context $\mathrm{C}$ following acquisition in context $\mathrm{A}$ and extinction in context B (Bouton and Bolles 1979b; Harris et al. 2000). The renewal effect is not due to context conditioning (Bouton and King 1983; Bouton and Swartzentruber 1986), but rather appears to reflect an occasion-setting (cf. Swartzentruber 1995) or modulatory role of context in gating performance to the CS (Bouton 1993).

Renewal often is considered to be the most convincing demonstration of inhibition in extinction because recovery of extinguished CRs is instantaneous and, in some cases, significant enough that pre-extinction training levels of responding are nearly re-attained. Importantly, renewal does not seem to be mitigated by overtraining of extinction, meaning that CR return is observed even following extensive extinction training well beyond the point at which behavioral CRs have disappeared (Rauhut et al. 2001). Hence, a lack of renewal following shortinterval extinction would be difficult to attribute to facilitated inhibition as opposed to some other mechanism, such as erasure.

The experimental protocol is shown schematically in the top panel of Figure 2. Rats were trained with 15 light-shock pairings, then at one of four intervals thereafter $(10 \mathrm{~min}$ or $1 \mathrm{~h}, 24 \mathrm{~h}$, or $72 \mathrm{~h}$ ) were extinguished with 90 unshocked light presentations in either our standard experimental context (the same context that had been used for acquisition) or a modified, discriminably different context (see Materials and Methods for details). Animals were returned to the standard context and tested for fear to the light $24 \mathrm{~h}$ after extinction training. The critical comparison in this experiment is between animals trained, extinguished, and tested within the standard context (denoted "AAA") and animals extinguished in a context different from that of training and test (denoted "ABA").

The results of the experiment are presented in the bottom panel of Figure 2. It is evident from the figure that there was differential renewal across the time-point groups, such that there was very little difference between the AAA and ABA conditions in the 10-min time point, but there was substantially greater fearpotentiated startle in the ABA condition than in the AAA condi-

A

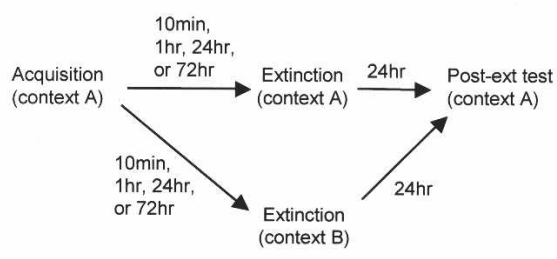

B

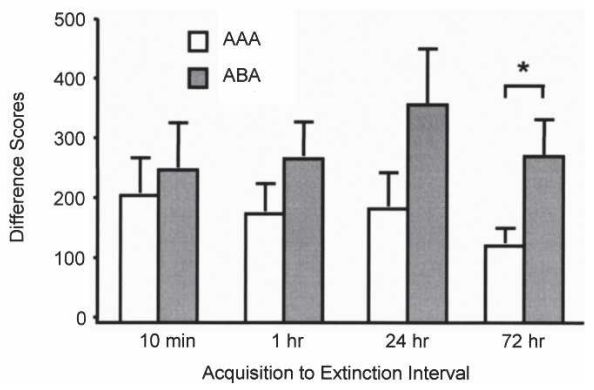

Figure 2. (A) Training protocol, Experiment 2. (B) Animals extinguished at intervals of $10 \mathrm{~min}, 1 \mathrm{~h}, 24 \mathrm{~h}$, or $72 \mathrm{~h}$ after fear acquisition exhibited differential susceptibility to renewal. Shown are mean $(+/-$ SEM) fear-potentiated startle difference scores to a light CS in context $A$ following extinction training in either context $A$ (denoted "AAA") or context $B$ (denoted "ABA"). Significant differences $(P<0.05)$ are indicated by an asterisk. 
tion in the 72-h group. Consistent with these observations, an ANOVA with Time Point (10 min, $1 \mathrm{~h}, 24 \mathrm{~h}, 72 \mathrm{~h}$ ) and Condition (AAA, ABA) as between-groups factors revealed a significant main effect of Condition, $F_{1,83}=7.02, P=0.010$, but not Time Point, $F<1$. However, the interaction between these factors did not reach significance, $F<1$. Planned comparisons of the AAA and ABA conditions within each time point revealed significant renewal in the 72-h group only, $t_{(26)}=2.23, P=0.035$. Renewal was not significant in the 24-h, 1-h, and 10-min groups, as indicated by independent samples $t$-tests: $24 \mathrm{~h}, t_{(17)}=1.58, P=0.132 ; 1 \mathrm{~h}$, $t_{(26)}=1.22, P=0.233 ; 10 \mathrm{~min}, t_{(14)}=0.45, P=0.657$.

There appeared to be differences among the time-point groups in the AAA condition, such that animals extinguished 72 $\mathrm{h}$ after acquisition showed more robust extinction than did animals in any of the other time-point groups. However, a one-way ANOVA comparing responding in the AAA condition across the time-point groups revealed no significant simple main effect, $F<1$.

The lack of significant renewal in the short-interval groups in this experiment is consistent with the finding of the previous experiment that animals extinguished shortly after acquisition do not show reinstatement. This provides a second, independent piece of evidence that the mechanism of short-interval extinction differs from that of long-interval extinction. Importantly, the lack of significant renewal in the early time-point groups is not easily accounted for by facilitated inhibition, because renewal is known to occur even following extensive overtraining of extinction, a circumstance that would seem to favor the development of an especially strong inhibitory association (Rauhut et al. 2001). This then would seem to suggest that the mechanism of short-interval extinction differs qualitatively from that of longinterval extinction, such that it is not due to inhibitory learning but, rather, involves some other mechanism, such as erasure.

\section{Experiment 3: Spontaneous recovery}

A third test for return of fear following extinction is spontaneous recovery, which refers to a reappearance of extinguished CRs with the passage of time following extinction in the absence of any further explicit training. Pavlov (1927) was the first to observe spontaneous recovery and he was sufficiently impressed by it to conclude that extinction cannot constitute unlearning, but rather must result from some inhibitory process. Others, such as Skinner (1950), argued that spontaneous recovery could be accounted for in terms of handling cues acting as a signal of the impending delivery of the US, although findings suggesting that spontaneous recovery is observed even when test trials are inserted into the middle of a session have argued against that idea (Thomas and Sherman 1986; Robbins 1990). Hence, spontaneous recovery is taken to be a third phenomenon indicating that the CR-eliciting ability of a CS is not lost in extinction, but rather is actively inhibited at some level.

The experimental protocol is shown schematically in the top panel of Figure 3. Rats were trained with 15 light-shock pairings, then were extinguished with 90 light presentations in the absence of footshock at one of three time points thereafter (10 min, $1 \mathrm{~h}$, or $72 \mathrm{~h}$ ). The 24 -h time point was not included in this experiment because the prior data were somewhat equivocal at this time point. Half of the animals of each time point were tested for fear-potentiated startle to the light $1 \mathrm{~d}$ later and the remaining half were tested $21 \mathrm{~d}$ later. Hence, the measure of interest in this experiment was the comparison between the 1-d and 21-d groups, with spontaneous recovery consisting of greater fear-potentiated startle in the 21-d test than in the 1-d test.

The data are presented in the bottom panel of Figure 3 . Inspection of the figure indicates different degrees of spontane-
A

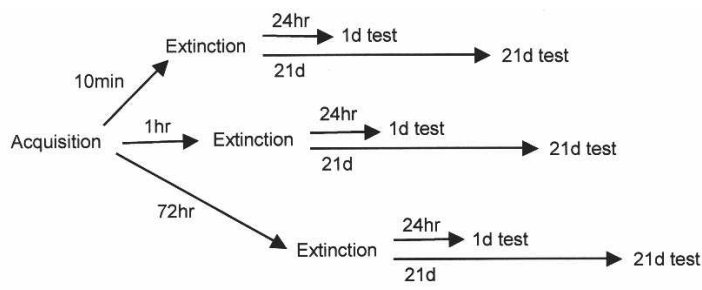

B

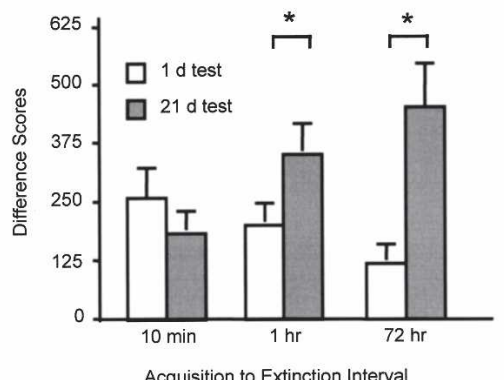

Figure 3. (A) Training protocol, Experiment 3. (B) Animals extinguished at intervals of $10 \mathrm{~min}, 1 \mathrm{~h}$, or $72 \mathrm{~h}$ after fear acquisition exhibited differential susceptibility to spontaneous recovery. Shown are mean (+/ SEM) fear-potentiated startle difference scores to a light CS in tests conducted $1 \mathrm{~d}$ and $21 \mathrm{~d}$ after extinction training. Significant differences $(P<0.05)$ are indicated by an asterisk.

ous recovery in each of the three time-point groups, with the 72-h group exhibiting robust recovery of fear over time, the 1-h group exhibiting smaller but still notable fear recovery, and the 10-min group exhibiting no recovery at all. Statistical analysis supported these observations. An ANOVA with Time Point (10 min, $1 \mathrm{~h}, 72 \mathrm{~h})$ and Test $(1 \mathrm{~d}, 21 \mathrm{~d})$ as between-subjects factors revealed a significant main effect of Test, $F_{1,67}=7.61, P=0.007$, and a significant Time Point $\times$ Test interaction, $F_{2,67}=4.87$, $P=0.011$. The main effect of Time Point was not significant, $F<1$. Planned comparisons (via independent samples $t$-tests) of the 1-d and 21-d tests within each time point revealed significant spontaneous recovery in the 72-h group, $t_{(21)}=3.42, P=0.003$, and the 1-h group, $t_{(28)}=2.06, P=0.049$, but not the 10 -min group, $t_{(18)}=0.82, P=0.422$. A one-way ANOVA comparing performance in the 1-d test across all time points indicated that the simple main effect was not significant, $F_{2,35}=2.03, P=0.147$.

These findings are consistent with those of Experiments 1 and 2 in that the 72-h group showed recovery of fear but the 10-min group did not, indicating once again that the mechanism of short-interval extinction may differ from that of long-interval extinction. The recovery in the 1-h group came as a surprise in light of the lack of significant recovery in this group in previous experiments, although interestingly it is consistent with a report by Quirk (2002) of reliable spontaneous recovery of freezing over time following extinction conducted $1 \mathrm{~h}$ after acquisition. Thus it may be that spontaneous recovery is a particularly sensitive test of latent fear following extinction, and if so, it is especially telling that recovery is not detectable in the 10-min group.

\section{Experiment 4: Magnitude of extinction in the 10-min group}

Although the lack of recovery in the 10-min group is suggestive of an erasure mechanism, the relatively poor extinction in this group as compared to the 72-h group suggests another explanation: If the 10-min group did not extinguish significantly, then this group would not be expected to show increased fear following footshock, a shift of context, or the passage of time. In a 
fourth and final experiment, we examined the magnitude of extinction in the 10-min group (denoted "EXT") relative to a control group receiving equivalent context exposure but no nonreinforced light presentations (denoted "CTX"). If extinction training initiated $10 \mathrm{~min}$ after acquisition does, in fact, extinguish fear reliably, then the EXT group should exhibit significantly less fear-potentiated startle in a subsequent test session than does the CTX group.

As shown in Figure 4, this prediction was borne out. The reduced fear-potentiated startle in the EXT group relative to the CTX group was confirmed by an independent samples $t$-test, which indicated that the difference was significant, $t_{(22)}=2.11$, $P=0.046$.

The mean difference score of the 10-min extinction group in this experiment was lower than that in the previous three experiments. We routinely observe replication effects of this sort among cohorts of animals run at different times, and based on the relatively low mean fear-potentiated startle exhibited by the CTX group, it seems likely that the difference between this experiment and the others is in the amount of fear acquired as opposed to the efficacy of extinction. Nevertheless, to confirm that the lack of recovery in the 10-min extinction group in previous experiments was not in any way a function of that group's relatively high post-extinction test responding, we presented the EXT group in this experiment with five unsignaled footshocks and retested for reinstatement following the same general protocol as in Experiment 1. Consistent with the results of that experiment, there was no evidence of reinstatement, $t_{(12)}=-0.93$, $P=0.371$.

\section{Discussion}

In three experiments, extinction trained at an interval of $72 \mathrm{~h}$ following fear acquisition (long-interval extinction) was sensitive to disruption through reinstatement, renewal, and spontaneous recovery, whereas extinction trained at an interval of $10 \mathrm{~min}$ (short-interval extinction) was resistant to disruption through any of these means. Extinction trained at intermediate intervals was characterized by intermediate levels of fear recovery, such

A

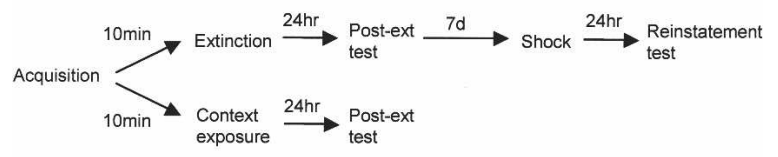

B

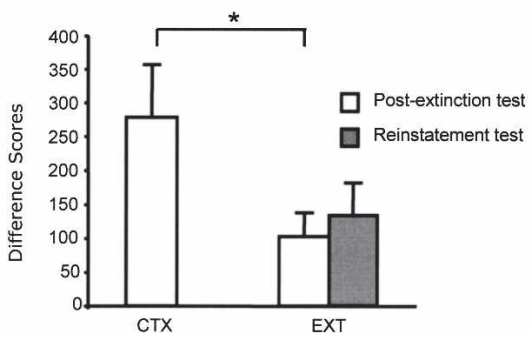

Figure 4. (A) Training protocol, Experiment 4. (B) Animals extinguished 10 min after acquisition (EXT) show significantly reduced fearpotentiated startle relative to animals given equivalent context exposure without nonreinforced light presentations (CTX), and they do not exhibit reinstatement following unsignaled shock presentations. Shown are mean $(+/-$ SEM) fear-potentiated startle difference scores. Significant differences $(P<0.05)$ are indicated by an asterisk. that a group extinguished $24 \mathrm{~h}$ after acquisition exhibited nominal reinstatement and renewal, and a group extinguished $1 \mathrm{~h}$ after acquisition exhibited neither reinstatement nor renewal but did exhibit spontaneous recovery. Because CR recovery following extinction is cited widely as evidence that extinction is an inhibitory learning process as opposed to an erasure of previous learning, the fact that significant recovery was not observed under any circumstances in the 10-min group would seem to indicate that short-interval extinction proceeds via a nontraditional mechanism that may most parsimoniously be described as erasure (but see below). It appears that the shift from a putative erasure mechanism toward a more traditional mechanism involving context- and time-dependent inhibition of fear occurs 24-72 $\mathrm{h}$ after acquisition.

Across Experiments 1-3, there was a trend toward poorer extinction in the short-interval groups than in the long-interval groups, as indicated by greater levels of fear-potentiated startle in the post-extinction test. In no single experiment was this effect significant, but it was observed consistently and does seem to be "real," and in fact a similar difference in the efficacy of 15-min versus 24 -h extinction has very recently been reported in experiments using freezing as a measure of conditioned fear (Maren and Chang 2005). It is especially interesting in light of this that the short-interval groups tended to resist recovery of fear, because it seems reasonable to suppose that poorer extinction should be associated with poorer retention of extinction. The fact that the opposite was observed may be another clue that shortinterval extinction involves a process akin to erasure. Importantly, Experiment 4 indicates that 10-min extinction training significantly reduced fear-potentiated startle relative to context exposure in the absence of nonreinforced light presentations, implying that neither ineffective extinction nor a ceiling effect explains the lack of recovery in the 10-min group.

We do not have any information about within-session extinction because we chose not to incorporate startle probes into extinction training sessions. This is because the startle-eliciting noise burst is itself mildly aversive and might interfere with or at least delay extinction if coupled with the light CS. Instead, we elected to assess extinction through a post-extinction test occurring $24 \mathrm{~h}$ after extinction training. The post-extinction test might itself be construed as an extinction training session, although this is unlikely to affect the interpretation of the results reported here. In Experiments 2 and 3, for example, the post-extinction test was the endpoint of the experiment and the critical comparison was between groups; hence, extinction occurring within the test session could not impact subsequent learning or performance.

Although it is tempting to conclude that erasure is the mechanism of short-interval extinction, a certain degree of caution is in order because erasure, by nature, is a difficult phenomenon to prove conclusively. Indeed, it may be impossible to prove that no fear remains following short interval extinction. The best option is to demonstrate through as many independent measures as possible that fear is not recoverable, as we have attempted to do here. There are additional tests that one might use as well; for example, if fear to the light CS truly were erased then the light should not be able to block conditioning to a neutral CS (Kamin 1968), or summate with an extinguished or weakly conditioned cue (Reberg 1972; Hendry 1982), or show any evidence of facilitated reacquisition upon further pairings with the US (Bouton et al. 2004). ${ }^{5}$ However, in order for these additional demonstrations to be workable, it is necessary for post-extinction responding to the light to be at or very close to zero, which was

${ }^{5}$ We thank Robert Rescorla for suggesting these additional means of assessing erasure. 
not the case in any of the experiments presented here. Presumably this is because a single extinction training session is not adequate to completely extinguish fear-potentiated startle using the parameters we have selected. It seems likely that multiple extinction training sessions would be the most efficient way of eliminating responding, but to do so would be to introduce multiple acquisition-to-extinction intervals, which would seem to complicate matters more than illuminate them. Alternatively, one might use a design in which the light is extinguished in compound with a second, comparably trained CS, and as a result extinction is facilitated (A.R. Wagner, M. Saavedra, and G. Lehmann, reported in Wagner 1969; Wagner and Rescorla 1972), although again it is not clear that doing so would not alter the mechanism in some way.

Hence, it seems likely that more conclusive evidence that short-interval extinction is an erasure process will come from neurobiological experiments. Investigations of the biochemical and molecular sequelae of short- and long-interval extinction might reveal differences consistent with the current understanding of "erasure" or "new learning" at that level of analysis. We would predict, for example, that expression and/or activity of the protein phosphatase calcineurin would be up-regulated specifically, or at least more robustly, following $10 \mathrm{~min}$ of extinction than following $72 \mathrm{~h}$ of extinction if indeed calcineurin is involved critically in synaptic depotentiation. In fact, we now have preliminary data consistent with this prediction (Myers et al. 2005). We also would predict that administration of a calcineurin inhibitor prior to extinction training would disrupt 10-min extinction but not 72-h extinction.

Also consistent with the idea of a changing mechanism of extinction is a recent report by Cain et al. (2005) that fear extinction initiated immediately following acquisition is insensitive to the L-type voltage-gated calcium channel (L-VGCC) blocker nifedipine, whereas extinction initiated $1 \mathrm{~h}$ or $3 \mathrm{~h}$ after acquisition is impaired. These investigators also concluded that extinction initiated at short intervals after acquisition may involve erasure of fear, and emphasized that the consolidation state of fear memory may be a major determinant of the mechanism of extinction. Specifically, they proposed that L-VGCC involvement in extinction is specific to instances in which extinction training is initiated at a sufficient delay that fear memory has consolidated, and the mechanism of extinction corresponds to context- and time-dependent inhibition of fear. On the other hand, when extinction training is initiated immediately or very shortly after acquisition, when fear memory has not yet fully consolidated, extinction proceeds via an L-VGCC-independent mechanism that may correspond to depotentiation or long-term depression (LTD).

The findings presented here with regard to spontaneous recovery are at odds with a recent report by Rescorla (2004) that spontaneous recovery is greater following short acquisition-toextinction intervals than following longer intervals. In a series of experiments using a magazine approach in rats and autoshaping in pigeons, Rescorla demonstrated that for two stimuli, S1 and S2, that had been trained at different intervals relative to a single extinction training session involving intermixed, nonreinforced presentations of both cues, spontaneous recovery was greater to the stimulus that had undergone acquisition in close temporal proximity to extinction training (S2) than to the stimulus that had undergone acquisition at a more remote time point ( $\mathrm{S} 1$ ). Rescorla interpreted these findings as supportive of theoretical accounts of extinction emphasizing the importance of recency of extinction training relative to acquisition in determining extinction- or acquisition-appropriate performance in test (e.g., Devenport 1998). At this point it remains unclear what is the source of the discrepancy between the present results and those of Rescorla because several procedural differences between the two studies could have contributed. The most obvious is the choice of an appetitive versus aversive conditioning paradigm. It could be that the relationship between extinction interval and extinction mechanism differs between these paradigms, and it will be necessary to perform head-to-head comparisons using similar parametrics to make that determination.

Finally, the lack of reinstatement in the short-interval extinction groups is reminiscent of a recent report of resistance to reinstatement in animals extinguished in the presence of Dcycloserine, a partial agonist of the NMDA receptor (Ledgerwood et al. 2004). In these experiments D-cycloserine (DCS) was administered in conjunction with an extinction training session conducted $24 \mathrm{~h}$ after fear acquisition. In addition to its apparent resistance to recovery, DCS-facilitated extinction is notable as well in its lack of cue specificity (Ledgerwood et al. 2005). It will be of interest, therefore, in future experiments to compare the cue specificity of short-interval extinction, long-interval extinction, and long-interval extinction in the presence of DCS. If both short-interval extinction and DCS-facilitated long-interval extinction lack cue specificity, then this together with the shared resistance to reinstatement would suggest that they proceed via a common mechanism. This could have significant clinical implications in light of the demonstrated clinical utility of DCS as a pharmacological adjunct to therapy in phobic patients (Ressler et al. 2004).

In summary, we have shown that short-interval extinction is less susceptible to fear recovery than is long-interval extinction, suggesting a mechanistic dissociation between the two. Future behavioral and neurobiological studies will explore that dissociation further and perhaps provide additional evidence that short-interval extinction is mediated by erasure of conditioned fear.

\section{Materials and Methods}

\section{Animals}

Male Sprague-Dawley rats (Charles River, Raleigh, NC) weighing $350-450 \mathrm{~g}$ were used. Animals were maintained on a 12-h light/ 12-h dark cycle (lights on at 0700) with food and water continuously available. All rats were group housed (four rats each) in a temperature-controlled $\left(24^{\circ} \mathrm{C}\right)$ animal colony.

\section{Apparatus}

Animals were trained and tested in $8 \times 15 \times 15$-cm Plexiglas and wire-mesh cages. The cage floor consisted of four $6.0-\mathrm{mm}$ diameter stainless-steel bars spaced $18 \mathrm{~mm}$ apart. Each cage was suspended between compression springs within a steel frame and located within a custom-designed $90 \times 70 \times 70$-cm ventilated sound-attenuating chamber. Background noise (60 dB wideband) was provided by a General Radio Type 1390-B noise generator and delivered through high-frequency speakers (Radio Shack Supertweeter; Tandy) located $5 \mathrm{~cm}$ in front of each cage. Sound level measurements (sound pressure level) were made with a Bruel \& Kjaer model 2235 sound-level meter (A scale; random input) with the microphone (Type 4176) located $7 \mathrm{~cm}$ from the center of the speaker (approximating the distance of the rat's ear from the speaker). A red lightbulb $(7.5 \mathrm{~W})$, located $25 \mathrm{~cm}$ from the stabilimeter, illuminated the chamber at all times.

Startle responses were evoked by $50-\mathrm{msec}$, $95-\mathrm{dB}$ white noise bursts ( 5 msec rise-decay) generated by a Macintosh G3 computer soundfile $(0-22 \mathrm{kHz})$, amplified by a Radio Shack amplifier (100 W; model MPA-200; Tandy), and delivered through the same speakers used to provide background noise. An accelerometer (model U321A02; PCB Piezotronics) affixed to the bottom of each cage produced a voltage output proportional to the velocity of cage movement. This output was amplified and rectified to give cage velocity as the output (model 483B21; PCB Piezotron- 
ics) and digitized on a scale of 0-2500 arbitrary units by an InstruNET device (model 100B; GW Instruments) interfaced to a Macintosh G3 computer. Startle amplitude was defined as the maximal peak-to-peak voltage that occurred during the first 200 msec after onset of the startle-eliciting stimulus.

A 3.7-sec light CS (80 lux) was produced by an $8 \mathrm{~W}$ fluorescent bulb (100 $\mu \mathrm{sec}$ rise time) located $10 \mathrm{~cm}$ behind each cage. Luminosity was measured using a VWR light meter. The US was a 0.5 -sec shock that was delivered to the floorbars and produced by a shock generator (SGS-004; LeHigh Valley). Shock intensities (measured as in Cassella and Davis 1986) were $0.4 \mathrm{~mA}$.

The presentation and sequencing of all stimuli were under the control of the Macintosh G3 computer using customdesigned software (The Experimenter; Glassbeads Inc.).

\section{Context shift}

The experimental chambers were modified in the following ways to afford a change of context: The grid bars were covered with a floor insert consisting of coarse sandpaper adhered to a cardboard cutout; four Velcro strips were adhered to the left and right walls; two ball chains were suspended from the ceiling of the chamber; a continuous tactile stimulus was provided by $12-\mathrm{V}$ DC, 3-in brushless computer fans (Radio Shack; model \#273-243) mounted to the top exterior portion of each startle cage; and the background noise was set to $80 \mathrm{~dB}$.

\section{Procedure}

\section{Matching}

On each of two days, rats were placed into the startle chambers and 5 min later presented with 30 startle stimuli (95 dB; 30-sec interstimulus interval-ISI). The rats subsequently were matched into groups exhibiting similar mean startle amplitude based on the 30 startle stimuli of the second matching session.

\section{Fear acquisition}

Twenty-four hours after the second matching session, rats were returned to the startle chambers and $5 \mathrm{~min}$ later received the first of 15 presentations of a 3.7-sec light that coterminated with a 0.5-sec, 0.4-mA footshock. The mean intertrial interval (ITI; defined as the interval between the onsets of successive CSs) was 2 min (range $=1-3 \mathrm{~min}$ ). Immediately after the final training event, rats were removed from the chambers and returned to their home cages.

\section{Extinction training}

Extinction training commenced $10 \mathrm{~min}, 1 \mathrm{~h}, 24 \mathrm{~h}$, or $72 \mathrm{~h}$ after fear acquisition and consisted of the presentation of 903.7 -sec lights in the absence of footshock. Lights were presented in three blocks of 30 trials with a 30 -sec ITI within each block. Blocks were separated by 5 -min intervals in which animals remained in the experimental chambers but received no explicit stimulation. Immediately after the final light presentation, rats were removed from the chambers and returned to their home cages.

\section{Testing}

Testing for fear-potentiated startle occurred at prescribed intervals after extinction training. Test sessions began with the presentation of 30 startle stimuli (leaders) at a 30-sec ITI to habituate the startle response to a stable baseline. The data from these trials were not examined further. Twenty additional startle stimuli followed immediately thereafter, 10 of which were presented $3.2 \mathrm{sec}$ after the onset of the 3.7-sec light. Fear-potentiated startle was defined as an increase in the amplitude of the acoustically elicited startle response in the presence versus the absence of the light and was quantified as difference scores, that is, startle amplitude in the presence of the light minus startle in the absence of the light.

\section{Reinstatement}

In the reinstatement experiments, animals were exposed to a single session of unsignaled footshocks after the completion of extinction training. Five minutes after being placed into the chambers, rats received the first of five 0.4-mA footshocks occurring at a 2-min vITI (range $=1-3 \mathrm{~min}$ ). No lights were presented during this session. The rats were removed from the chambers and returned to their homecages immediately after the fifth footshock.

\section{Acknowledgments}

The authors thank the participants in the conference entitled "Extinction: The Neural Mechanisms of Behavior Change," held in Ponce, Puerto Rico, February 2-5, 2005, for much useful discussion of the issues raised by this work. In particular we acknowledge, in no particular order, the following individuals: Gregory Quirk, Mark Barad, Robert Rescorla, Mark Bouton, Ken Lukowiak, and Michael Mauk. We also thank Allan Wagner for his many helpful comments. This work was supported by $\mathrm{MH}$ 47840 (to M.D.), the Woodruff Foundation, and the STC Program of the NSF under Agreement No. IBN-9876754.

\section{References}

Aroniadou-Anderjaska, V., Post, R.M., Rogawski, M.A., and Li, H. 2001. Input-specific LTP and depotentiation in the basolateral amygdala. Neuroreport 12: 635-640.

Berretta, S., Pantazopoulos, H., Caldera, M., Pantazopoulos, P., and Pare, D. 2005. Infralimbic cortex activation increases c-Fos expression in intercalated neurons of the amygdala. Neuroscience 132: 943-953.

Bouton, M.E. 1993. Context, time and memory retrieval in the interference paradigms of Pavlovian conditioning. Psychol. Bull. 114: $80-99$

Bouton, M.E. and Bolles, R.C. 1979a. Role of contextual stimuli in reinstatement of extinguished fear. J. Exp. Psychol. Anim. Behav. Process. 5: 368-378.

. 1979b. Contextual control of the extinction of conditioned fear. Learn. Motiv. 10: 455-466.

Bouton, M.E. and King, D.A. 1983. Contextual control of the extinction of conditioned fear: Tests for the associative value of the context. J. Exp. Psychol. Anim. Behav. Process. 9: 248-265.

Bouton, M.E. and Swartzentruber, D. 1986. Analysis of the associative and occasion setting properties of contexts participating in a Pavlovian discrimination. J. Exp. Psychol. Anim. Behav. Process. 12: $333-350$.

Bouton, M.E., Woods, A.M., and Pineño, O. 2004. Occasional reinforced trials during acquisition can slow the rate of rapid reacquisition. Learn. Motiv. 35: 371-390.

Cain, C.K., Blouin, A.M., and Barad, M. 2001. L-type voltage-gated calcium channels are required for extinction, but not for acquisition or expression, of conditional fear in mice. J. Neurosci. 22: $9113-9121$.

Cain, C.K., Godsil, B.P., Jami, S., and Barad, M. 2005. The L-type calcium channel blocker nifedipine impairs extinction, but not reduced contingency effects, in mice. Learn. Mem. 12: 277-284.

Cannich, A., Wotjak, C.T., Kamprath, K., Hermann, H., Lutz, B., and Marsicano, G. 2004. CB1 cannabinoid receptors modulate kinase and phosphatase activity during extinction of conditioned fear in mice. Learn. Mem. 11: 625-632.

Cassella, J.V. and Davis, M. 1986. The design and calibration of a startle measurement system. Physiol. Behav. 36: 377-383.

Chen, X., Garelick, M.G., Wang, H., Li, V., Athos, J., and Storm, D.R. 2005. PI3 kinase signaling is required for retrieval and extinction of contextual memory. Nat. Neurosci. 8: 925-931.

Chhatwal, J.P., Myers, K.M., Ressler, K.J., and Davis, M. 2005. Regulation of gephyrin and GABAA receptor binding within the amygdala after fear acquisition and extinction. J. Neurosci. 25: 502-506.

Davis, M. 2000. The role of the amygdala in conditioned and unconditioned fear and anxiety. In The amygdala: A functional analysis (ed. J.P. Aggleton), pp. 213-287. Oxford University Press, New York.

Davis, M. and Myers, K.M. 2002. The role of glutamate and $\gamma$-aminobutryic acid in fear extinction: Clinical implications for exposure therapy. Biol. Psychiatry 52: 998-1007.

Delamater, A.R. 2004. Experimental extinction in Pavlovian conditioning: Behavioural and neuroscience perspectives. Q. J. Exp. Psychol. B 57: 97-132.

Devenport, L.D. 1998. Spontaneous recovery without interference: Why remembering is adaptive. Anim. Learn. Behav. 26: 172-181.

Falls, W.A., Miserendino, M.J., and Davis, M. 1992. Extinction of fear-potentiated startle: Blockade by infusion of an NMDA antagonist into the amygdala. J. Neurosci. 12: 854-863.

\section{Learning \& Memory}


Fischer, A., Sananbenesi, F., Schrick, C., Spiess, J., and Radulovic, J. 2004. Distinct roles of hippocampal de novo protein synthesis and actin rearrangement in extinction of conditioned fear. J. Neurosci. 24: 1962-1966.

Fujii, S., Saito, K., Miyakawa, H., Ito, K., and Kato, H. 1991. Reversal of long-term potentiation (depotentiation) induced by tetanus stimulation of the input to CA1 neurons of guinea pig hippocampal slices. Brain Res. 555: 112-122.

Gale, G.D., Anagnostaras, S.G., Godsil, B.P., Mitchell, S., Nozawa, T., Sage, J.R., Wiltgen, B., and Fanselow, M.S. 2004. Role of the basolateral amygdala in the storage of fear memories across the adult lifetime of rats. J. Neurosci. 24: 3810-3815.

Harris, J.A. and Westbrook, R.F. 1998. Evidence that GABA transmission mediates context-specific extinction of learned fear. Psychopharmacology 140: 105-115.

Harris, J.A., Jones, M.L., Bailey, G.K., and Westbrook, R.F. 2000. Contextual control over conditioned responding in an extinction paradigm. J. Exp. Psychol. Anim. Behav. Process. 26: 174-185.

Hendry, J.S. 1982. Summation of undetected excitation following extinction of the CER. Anim. Learn. Behav. 10: 476-482.

Hobin, J.A., Goosens, K.A., and Maren, S. 2003. Context-dependent neural activity in the lateral amygdala represents fear memories after extinction. J. Neurosci. 23: 8410-8416.

Huang, C.C., Liang, Y.C., and Hsu, K.-S. 2001. Characterization of the mechanism underlying the reversal of long-term potentiation by low frequency stimulation at hippocampal CA1 synapses. J. Biol. Chem. 276: $48108-48117$.

Kamin, L.J. 1968. Attention-like processes in classical conditioning. In Miami symposium on the prediction of behavior: Aversive stimulation (ed. M.R. Jones), pp. 9-33. University of Miami Press, Miami, FL.

Lattal, K.M. and Abel, T. 2001. Different requirements for protein synthesis in acquisition and extinction of spatial preferences and context-evoked fear. J. Neurosci. 21: 5773-5780.

Lattal, K.M., Honarvar, S., and Abel, T. 2004. Effects of post-session injections of anisomycin on the extinction of a spatial preference and on the acquisition of a spatial reversal preference. Behav. Brain Res. 153: 327-339.

Ledgerwood, L., Richardson, R., and Cranney, J. 2004. D-Cycloserine and the facilitation of extinction of conditioned fear: Consequences for reinstatement. Behav. Neurosci. 118: 505-513.

. 2005. D-Cycloserine facilitates extinction of learned fear: Effects on reacquisition and generalized extinction. Biol. Psychiatry 57: 841-847.

Lin, C.-H., Yeh, S.-H., Leu, W.-C., Chang, W.-C., Wang, S.-T., and Gean, P.-W. 2003a. Identification of calcineurin as a key signal in the extinction of fear memory. J. Neurosci. 23: 1574-1579.

Lin, C.-H., Yeh, S.-H., Lu, H.-S., and Gean, P.-W. 2003b. The similarities and diversities of signal pathways leading to consolidation of conditioning and consolidation of extinction of fear memory. $J$. Neurosci. 23: 8310-8317.

Lin, C.-H., Lee, C.-C., and Gean, P.-W. 2003c. Involvement of a calcineurin cascade in amygdala depotentiation and quenching of fear memory. Mol. Pharmacol. 63: 44-52.

Lin, C.-H., Lee, C.-C., Huang, Y.-C., Wang, S.-J., and Gean, P.-W. 2005. Activation of group II metabotropic glutamate receptors induces depotentiation in amygdala slices and reduces fear-potentiated startle in rats. Learn. Mem. 12: 130-137.

Lu, K.-T., Walker, D.L., and Davis, M. 2001. Mitogen-activated protein kinase cascade in the basolateral nucleus of amygdala is involved in extinction of fear-potentiated startle. J. Neurosci. 15: RC162 (1-5).

Malinow, R. and Malenka, R.C. 2002. AMPA receptor trafficking and synaptic plasticity. Annu. Rev. Neurosci. 25: 103-126.

Maren, S. and Chang, C. 2005. Temporal factors regulate fear extinction in rats. Poster presented at the 35th annual meeting of the Society for Neuroscience, Washington, DC.

Milad, M.G. and Quirk, G.J. 2002. Neurons in medial prefrontal cortex signal memory for fear extinction. Nature 420: 70-74.

Myers, K.M. and Davis, M. 2002. Behavioral and neural analysis of extinction. Neuron 36: 567-584.

Myers, K.M., Ressler, K.J., and Davis, M. 2005. Different mechanisms of fear extinction dependent on length of time since acquisition. Abstract Viewer Itinerary Planner, Program No. 70.1. Society for Neuroscience, Washington, DC.

Pavlov, I.P. 1927. Conditioned reflexes. Oxford University Press, London.

Quirk, G.J. 2002. Memory for extinction of conditioned fear is long-lasting and persists following spontaneous recovery. Learn. Mem. 9: 402-406.

Quirk, G.J. and Gehlert, D.R. 2003. Inhibition of the amygdala: Key to pathological states? Ann. NY Acad. Sci. 985: 263-272.

Quirk, G.J., Russo, G.K., Barron, J.L., and Lebron, K. 2000. The role of ventromedial prefrontal cortex in recovery of extinguished fear. $J$ Neurosci. 20: 6225-6231.
Quirk, G.J., Likhtik, E., Pelletier, J.G., and Pare, D. 2003. Stimulation of medial prefrontal cortex decreases the responsiveness of central amygdala output neurons. J. Neurosci. 23: 8800-8807.

Rauhut, A.S., Thomas, B.L., and Ayres, J.J. 2001. Treatments that weaken Pavlovian conditioned fear and thwart its renewal in rats: Implications for treating human phobias. J. Exp. Psychol. Anim. Behav. Process. 27: 99-114.

Reberg, D. 1972. Compound tests for excitation in early acquisition and after prolonged extinction of conditioned suppression. Learn. Motiv. 3: $246-258$.

Repa, J.C., Muller, J., Apergis, J., Desrochers, T.M., Zhou, Y., and LeDoux, J.E. 2001. Two different lateral amygdala cell populations contribute to the initiation and storage of memory. Nat. Neurosci. 4: 724-731.

Rescorla, R.A. 2004. Spontaneous recovery varies inversely with the training-extinction interval. Learn. Behav. 32: 401-408.

Rescorla, R.A. and Heth, C.D. 1975. Reinstatement of fear to an extinguished conditioned stimulus. J. Exp. Psychol. Anim. Behav. Process. 1: 88-96.

Ressler, K.J., Rothbaum, B.O., Tannenbaum, L., Anderson, P., Graap, K., Zimand, E., Hodges, L., and Davis, M. 2004. Cognitive enhancers as adjuncts to psychotherapy: Use of D-cycloserine in phobic individuals to facilitate extinction of fear. Arch. Gen. Psychiatry 61: $1136-1144$.

Riedel, G. 1999. If phosphatases go up, memory goes down. Cell. Mol. Life Sci. 55: 549-553.

Robbins, S.J. 1990. Mechanisms underlying spontaneous recovery in autoshaping. J. Exp. Psychol. Anim. Behav. Process. 16: 235-249.

Rodrigues, S.M., Schafe, G.E., and LeDoux, J.E. 2004. Molecular mechanisms underlying emotional learning and memory in the lateral amygdala. Neuron 44: 75-91.

Rosenkranz, J.A., Moore, H., and Grace, A.A. 2003. The prefrontal cortex regulates lateral amygdala neuronal plasticity and responses to previously conditioned stimuli. J. Neurosci. 23: 11054-11064.

Santini, E., Ge, H., Ren, K., Peña de Ortiz, S., and Quirk, G.J. 2004. Consolidation of fear extinction requires protein synthesis in the medial prefrontal cortex. J. Neurosci. 24: 5704-5710.

Skinner, B.F. 1950. Are theories of learning necessary? Psychol. Rev. 57: 193-216.

Staubli, U. and Chun, D. 1996. Factors regulating the reversibility of long-term potentiation. J. Neurosci. 16: 853-860.

Swartzentruber, D. 1995. Modulatory mechanisms in Pavlovian conditioning. Anim. Learn. Behav. 23: 123-143.

Szapiro, G., Vianna, M.R., McGaugh, J.L., Medina, J.H., and Izquierdo, I. 2003. The role of NMDA glutamate receptors, PKA, MAPK, and CaMKII in the hippocampus in extinction of conditioned fear. Hippocampus 13: 53-58.

Thomas, D.R. and Sherman, L. 1986. An assessment of the role of handling cues in "spontaneous recovery" after extinction. J. Exp. Anal. Behav. 46: 305-314.

Vianna, M.R., Szapiro, G., McGaugh, J.L., Medina, J.H., and Izquierdo, I. 2001. Retrieval of memory for fear-motivated training initiates extinction requiring protein synthesis in the rat hippocampus. Proc. Natl. Acad. Sci. 98: 12251-12254.

Wagner, A.R. 1969. Stimulus selection and a "modified continuity theory." In The psychology of learning and motivation (eds. G.H. Bower and J.T. Spence), Vol. 3, pp. 1-41. Academic Press, New York.

Wagner, A.R. and Rescorla, R.A. 1972. Inhibition in Pavlovian conditioning: Application of a theory. In Inhibition and learning (eds. R.A. Boakes and M.S. Halliday), pp. 301-336. Academic Press, London.

Walker, D.L., Ressler, K.J., Lu, K.-T., and Davis, M. 2002. Facilitation of conditioned fear extinction by systemic administration or intra-amygdala infusions of D-cycloserine as assessed with fear-potentiated startle in rats. J. Neurosci. 22: 2343-2351.

Waltereit, R. and Weller, M. 2003. Signaling from cAMP/PKA to MAPK and synaptic plasticity. Mol. Neurobiol. 27: 99-106.

Westbrook, R.F., Iordanova, M., McNally, G., Richardson, R., and Harris, J.A. 2002. Reinstatement of fear to an extinguished conditioned stimulus: Two roles for context. J. Exp. Psychol. Anim. Behav. Process. 28: $97-110$.

Yang, Y.L. and Lu, K.T. 2005. Facilitation of conditioned fear extinction by $\mathrm{D}$-cycloserine is mediated by mitogen-activated protein kinase and phosphatidylinositol 3-kinase cascades and requires de novo protein synthesis in basolateral nucleus of amygdala. Neuroscience 134: $247-260$

Zhou, Q. and Poo, M.-M. 2004. Reversal and consolidation of activity-induced synaptic modifications. Trends Neurosci. 27: $378-383$.

Received October 13, 2005; accepted in revised form December 18, 2005. 


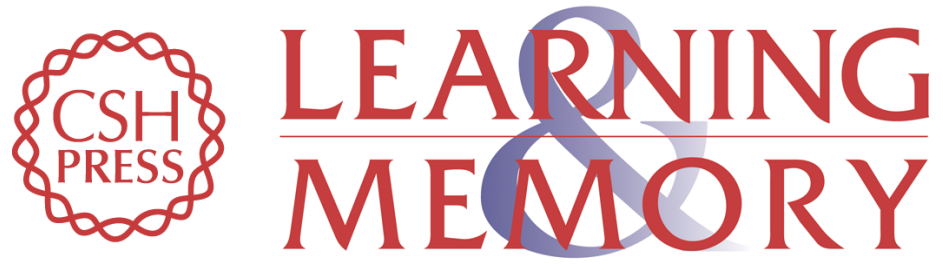

\section{Different mechanisms of fear extinction dependent on length of time since fear acquisition}

Karyn M. Myers, Kerry J. Ressler and Michael Davis

Learn. Mem. 2006, 13:

Access the most recent version at doi:10.1101/lm.119806

References This article cites 60 articles, 21 of which can be accessed free at:

http://learnmem.cshlp.org/content/13/2/216.full.html\#ref-list-1

License

Email Alerting Receive free email alerts when new articles cite this article - sign up in the box at the Service top right corner of the article or click here. 